\title{
Cerebroprotein Hydrolysate-I Inhibits Hippocampal Neuronal Apoptosis by Activating PI3K/Akt Signaling Pathway in Vascular Dementia Mice
}

\author{
Xiaolin $\mathrm{Wu}^{1,2}$ \\ Yingjuan $\mathrm{Liu}^{2}$ \\ Lin Zhu ${ }^{2}$ \\ Yue Wang ${ }^{2}$ \\ Yuqian Ren ${ }^{2}$ \\ Baohe Cheng ${ }^{3}$ \\ Leiming Ren ${ }^{4}$ \\ Keli Ge ${ }^{2}$ \\ Hongyun $\mathrm{Li}^{1}$
}

'Department of Neurology, The Affiliated Hospital of Qingdao University, Qingdao, Shandong, 266003, People's Republic of China; ${ }^{2}$ Institute of Integrative Medicine, School of Basic Medicine, Qingdao University, Qingdao, Shandong, 26602I, People's Republic of China; ${ }^{3}$ Shandong Haoyun Guoji Stem Cells Hospital, Jinan, Shandong, 25000I, People's Republic of China; ${ }^{4}$ Institute of Chinese Integrative Medicine, Hebei Medical University, Shijiazhuang, Hebei, 050017, People's Republic of China
Correspondence: Hongyun Li Department of Neurology, The Affiliated Hospital of Qingdao University, No. 16, Jiangsu Road, Shinan District, Qingdao, Shandong, People's Republic of China Email18661808653@163.com

Keli Ge

Institute of Integrative Medicine, School of Basic Medicine, Qingdao University, No. 38, Dengzhou Road, Shibei District, Qingdao, Shandong, People's Republic of China

Email ntfadu@163.com
Introduction: Vascular dementia (VaD), one of the brain injuries, is difficult to be cured, so it is important to take active neuroprotective treatment after its occurrence. Many studies have shown that apoptosis serves an important role in $\mathrm{VaD}$ occurrence; therefore, inhibition of apoptosis may contribute to the recovery of neurological function after $\mathrm{VaD}$ occurrence. Cerebroprotein hydrolysate-I (CH-I), a neuropeptide preparation which consists of several amino acids and small molecular peptides as the main active constituent, is extracted using a method similar to cerebrolysin (CBL) which has neuroprotective and neurotrophic effects. Methods: In the present study, a VaD model which was constructed using bilateral common carotid artery occlusion (BCCAO) in Kunming mice was applied to examine the neuroprotective effects of $\mathrm{CH}-\mathrm{I}$.

Results: The results show that $\mathrm{CH}-\mathrm{I}$ treatment could attenuate the decrease of learning and memory ability, cell apoptosis in the hippocampal CA1 region and inhibit the activation of caspase-3 and caspase-9 in VaD mice. Furthermore, CH-I treatment could also upregulate Bcl-2 protein levels and activate PI3K and Akt.

Discussion: We speculate that $\mathrm{CH}-\mathrm{I}$ may induce a neuroprotective effect activating PI3K/ Akt signaling pathway in $\mathrm{VaD}$ mice.

Keywords: vascular dementia, cerebroprotein hydrolysate-I, apoptosis, PI3K/Akt

\section{Introduction}

Vascular dementia $(\mathrm{VaD})$ is one of the brain injuries caused by cerebrovascular diseases, including ischemic injury and hemorrhagic injury, ${ }^{1}$ and has been the second most common form of dementia. ${ }^{2}$ By now, there is no exact definition of $\mathrm{VaD},{ }^{3}$ but decreased thinking ability caused by decrease of cerebral blood ${ }^{4}$ supply is referred to as the recognized symptom for identification of $\mathrm{VaD} .^{5}$

Because of the low cure rate, reducing occurrence and development of $\mathrm{VaD}$ that may be achieved by preventing the risk factors such as hypertension, smoking, ${ }^{5}$ diabetes, ${ }^{6}$ hypercholesterolemia, ${ }^{7}$ atherosclerosis ${ }^{8,9}$ and anxiety ${ }^{10}$ is extremely important for $\mathrm{VaD}$ treatment. Numerous studies have proved that, after $\mathrm{VaD}$ occurrence, extensive cell apoptosis leads to neuronal deaths over time. ${ }^{11-15}$ Therefore, inhibiting neuronal apoptosis may be an effective way to treat VaD.

Studies in recent years have shown that the brain protective agents can improve the symptoms of Alzheimer's disease and stroke, and have a certain effect on improving the cognitive ability and intelligence of patients. ${ }^{16,17}$ Cerebroprotein 
hydrolysate-I (CH-I), a neuropeptide preparation which consists of lysine, leucine, proline, isoleucine, phenylalanine, proline, methionine, tryptophan and other amino acids and small molecular peptides as the main active constituent, is extracted using a method similar to Cerebrolysin (CBL) which has neuroprotective and neurotrophic effects. ${ }^{18}$ In a recent study, it was found that CH-I mitigated stroke-induced white matter injury and facilitated axonal plasticity in the late stage after stroke. ${ }^{19}$ CBL can improve the cognitive ability and general function of $\mathrm{VaD}$ patients, ${ }^{20}$ attenuate apoptosis of thalamic neurons ${ }^{21}$ and improve the neurological function in middle cerebral artery occlusion (MCAO) rats. ${ }^{22}$ Therefore, we speculate that $\mathrm{CH}-\mathrm{I}$ and $\mathrm{CBL}$ may have similar neuroprotective effects.

In the present study, the effect of CH-I in VaD mice was explored.

\section{Materials and Methods}

\section{Animals}

Male Kunming (KM) mice weighing 25-30g were obtained from Pengyue Experimental Animal Breeding Co., Ltd. (SCXK 20190003) and maintained under a 12 $\mathrm{h}$ light/dark cycle with free access to water and food. The National Institutes of Health Guide for the Care and Use of Laboratory Animals was used as guidance in designing all animal-related studies. Approvals for the study were acquired from the Ethics Committee of Qingdao University Medical College (QYFY WZLL 26274).

\section{Reagents}

CH-I was obtained from Hebei Zhitong Biopharmaceutical Co., Ltd. (Hebei China). Cerebrolysin (CBL) was purchased from EVER Neuro Pharma GmbH, Austria. TUNEL Apoptosis detection kits were purchased from Boster Biological Technology Co., Ltd. CA, USA. Rabbit anti-mouse Akt (8200S), p-Akt (8200S), PI3K (4292S), p-PI3K (4228S), and anti-rabbit IgG HRP-linked antibody (7074P2) were purchased from Cell Signaling Technology Co., Ltd. Bcl-2 (ab182858) was purchased from Abcam, Cambridge, UK. caspase-3 Caspase-3 (AF6311), caspase-9 (AF6348), ECL Western Blotting Substrate were purchased from Affinity Co., Ltd. USA. BCA protein concentration determination kits were purchased from Biosharp Life Science Co., Ltd. USA.

\section{Behavioral Tests}

The method described by Zhang et $\mathrm{al}^{23}$ and Wei et $\mathrm{al}^{24}$ served as the reference. In the present study, a Y-maze electric stimulator (Institute of Materia Medica Chinese Academy of Medical Science) was used to train and test mice's learning and memory abilities.

Mice's memory ability was tested $24 \mathrm{~h}$ after training using the following method: record the number of correct responses and take the correct rate as the testing score (correct number/10 $\times 100 \%$ ). Higher accuracy rate means better memory ability for mice.

\section{Surgery and Model Construction}

The transient bilateral common carotid artery occlusion (BCCAO) surgery was performed as previously described and minor modifications were made on this basis. ${ }^{25,26}$ Briefly, the mice were anesthetized with chloral hydrate (460 mg/kg i.p.). After skin disinfection, a midline anterior neck incision was made, the bilateral common carotid arteries were carefully separated from the adjacent vagus nerve and were locked by aneurysm clips for $20 \mathrm{~min}$, followed by a release for $10 \mathrm{~min}$, and this operation was repeated two times. The state of the mouse and suture were observed after the cycle was completed. Only the left and right common carotid arteries were separated and the aneurysm clips were not used in sham-operated animals.

\section{Experimental Groups and Intervention}

The 60 healthy adult KM mice were randomly divided into sham operation group (10 cases) and BCCAO operation group (50 cases). The mice under BCCAO operation were randomly divided into five groups: $\mathrm{VaD}$ model group ( $\mathrm{VaD})$, low dose CH-I administration group (CH-I-L, $10 \mathrm{mg} / \mathrm{kg}$ ), medium dose CH-I administration group (CH-I-M, 20mg/ $\mathrm{kg}$ ), high dose CH-I administration group (CH-I-H, 30mg $/ \mathrm{kg}$ ) and $\mathrm{CBL}$ administration group (CBL, $10 \mathrm{mg} / \mathrm{kg}$ ), and each group included 10 mice. After 7 days, the learning and memory abilities of all mice were tested by the Y-maze. The mice in the sham group and the $\mathrm{VaD}$ group were injected with $0.5 \mathrm{~mL}$ of $0.9 \%$ normal saline every day, the mice in CH-I-L, CHI-M and CH-I-H groups were administered $\mathrm{CH}-\mathrm{I}$ at 10, 20, $30 \mathrm{mg} / \mathrm{kg}$, respectively, and the CBL group was administered $\mathrm{CBL}$ at $10 \mathrm{mg} / \mathrm{kg}$. All mice were treated with intraperitoneal injection, $0.5 \mathrm{~mL} / \mathrm{d}$, for 4 consecutive weeks. After the last administration, the surviving mice $(\mathrm{n}=8)$ of each group were subjected to behavioral tests. 


\section{HE Staining}

Four mice in each group were anesthetized by intraperitoneal injection of $10 \%$ chloral hydrate, and the heart was perfused with $20 \mathrm{~mL}$ of normal saline and $20 \mathrm{~mL}$ of $4 \%$ paraformaldehyde. The brain was completely removed, dehydrated, waxed, embedded, and serial coronal sections $(8 \mu \mathrm{m})$ patch spared. The paraffin sections were taken, deparaffinized and hydrated, stained with hematoxylin (G1120, Solarbio, CN) for $3 \mathrm{~min}$, differentiated for $10 \mathrm{~s}$, soaked in tap water for 15 min, stained with eosin (G1120, Solarbio, CN) for 1 min, and the color development was stopped in tap water. Conventional dehydrated, transparent, and neutral balsam seals were applied.The hippocampus structure was observed under a light microscope, and the nucleus and the cytoplasm showed blue and red, respectively. Five non-overlapping fields on each slice were recorded by optical microscope (IX70, OLYMPUS, JPN). The degree of damage is expressed by the denatured cell index (DCI, number of denatured cells/total number of cells).

\section{Nissl Staining}

The paraffin sections were taken, deparaffinized and hydrated, then the sections were put into cresyl violet stain (G1430, Solarbio, CN) at $56^{\circ} \mathrm{C}$ for $1 \mathrm{~h}$. After being soaked in deionized water, the sections were put into Nissl Differentiation (G1430, Solarbio, CN) at room temperature for $1 \mathrm{~min}$. Conventional dehydrated, transparent, and neutral balsam seals were applied. The hippocampus structure is observed under a light microscope. The positive neurons were clear and intact, and intracellular dyeing is blue-violet. The degree of damage is expressed by the denatured cell index (DCI, number of denatured cells/total number of cells)

\section{TUNEL Staining}

TUNEL assay kits were used for the analysis of cell apoptosis according to the manufacturer's instructions. The cells with brown particles in the nucleus under light microscope are considered as apoptotic cells. Part of the sections added $0.1 \mathrm{M}$ PBS as probe, and there was no positive reaction. Four serial sections from each mouse were taken and brown cell numbers in four random regions were counted in each section.

\section{Western Blotting}

Four mice were taken from each group and 10\% chloral hydrate was injected intraperitoneally for anesthesia, and the brains were taken after infusion of $20 \mathrm{~mL}$ normal saline through the heart. The hippocampus tissue was taken on ice and lysed with RIPA lysis buffer and then centrifuged at $4{ }^{\circ} \mathrm{C}$ for $15 \mathrm{~min}$. For each group, $20 \mu \mathrm{g}$ protein determined using BCA assay was separated by SDS-PAGE gel (10-15\%) and transferred to a PVDF membrane. After blocking with 5\% non-fat milk at room temperature for $1 \mathrm{~h}$, the membranes were incubated with primary antibodies at $4{ }^{\circ} \mathrm{C}$ overnight. The signals were detected using an enhanced chemiluminescence system. The gel imaging analysis system measures the gray value of each band, and expresses the protein level in terms of relative value of protein (RVP, gray value of target protein/gray value of internal reference protein).

\section{Statistical Analysis}

Statistical analysis was performed with SPSS 20.0 software, and the data were presented as mean \pm standard deviation $(\bar{X}$ $\pm \mathrm{S}$ ), using Student's $t$-test for two-group comparisons or one-way ANOVA for multiple-group comparisons. A p-value of less than 0.05 was considered significant.

\section{Results \\ $\mathrm{CH}-\mathrm{I}$ Improved Learning and Memory Ability of $\mathrm{VaD}$ Mice}

As shown in Table 1, there was no significant difference in the number of learning times required to reach the target in each group $(p>0.05)$. After modeling, the number of attempts significantly increased in all modeling mice compared with sham group $(p<0.01)$, indicating that the learning ability of mice significantly decreased, that is, the modeling was successful. Compared with sham group, the number of attempts in $\mathrm{VaD}$ group, $\mathrm{CH}-\mathrm{I}-\mathrm{H}$ group

Table I Comparison of Learning Ability of Mice in Each Group $(\bar{X} \pm$ S)

\begin{tabular}{|l|c|c|c|}
\hline & $\begin{array}{c}\text { Before } \\
\text { Modeling }\end{array}$ & $\begin{array}{c}\text { After } \\
\text { Modeling }\end{array}$ & $\begin{array}{c}\text { After } \\
\text { Treatment }\end{array}$ \\
\hline Sham & $29 \pm 4.22$ & $20.88 \pm 7.57$ & $27.5 \pm 4.84$ \\
$\mathrm{VaD}$ & $29.1 \pm 7.92$ & $40.1 \pm 7.4^{* *}$ & $47.25 \pm 5.18^{* *}$ \\
$\mathrm{CH}-\mathrm{I}-\mathrm{L}$ & $29 \pm 6.32$ & $39.75 \pm 6.4 I^{* *}$ & $34.88 \pm 5.08^{\# \#}$ \\
$\mathrm{CH}-\mathrm{I}-\mathrm{M}$ & $30 \pm 8.76$ & $42.25 \pm 8.35^{* *}$ & $34.88 \pm 5.08^{\# \#}$ \\
$\mathrm{CH}-\mathrm{I}-\mathrm{H}$ & $27.9 \pm 8.33$ & $43.38 \pm 4.72^{* *}$ & $38.5 \pm 7.07^{* \#}$ \\
$\mathrm{CBL}$ & $27 \pm 8.43$ & $4 I \pm 5.35^{* *}$ & $37.25 \pm 7.44^{* \#}$ \\
\hline
\end{tabular}

Notes: ${ }^{*} p<0.01$ vs sham; ${ }^{* *} p<0.01$ vs sham; ${ }^{\#}<0.05$ vs VaD; ${ }^{\#} p<0.01$ vs VaD. 
$(P<0.05)$ and CBL group $(p<0.01)$ significantly increased. Compared with the VaD group, the number of attempts of $\mathrm{CH}-\mathrm{I}$-treated and CBL group mice significantly decreased ( $p<0.05$ and $p<0.01$, respectively).

As shown in Table 2, compared with sham group, the success rate of each model mouse significantly decreased $(p<0.05)$. Compared with the VaD group, the success rate of CH-I-L and CH-I-M groups significantly increased $(p<0.01)$, but there was no significant difference between $\mathrm{CH}-\mathrm{I}-\mathrm{H}$ or $\mathrm{CBL}$ group and $\mathrm{VaD}$ group.

\section{HE Staining Shows That $\mathrm{CH}-\mathrm{I}$ Reduced the Number of Abnormal Nerve Cells in the Hippocampal CAI Regions of $\mathrm{VaD}$ Mice}

As shown in Figure 1, compared with sham group, the denaturation of hippocampal neurons in $\mathrm{VaD}$ group significantly increased $(p<0.01)$. The hippocampal CA1 region of mice in the $\mathrm{VaD}$ group displayed increased abnormal cell morphology, with reduced volume, darker staining, loose structure, disordered arrangement, and nuclei solid shrinkage. After treatment, the number of degenerated hippocampal cells in CH-I-treated group and CBL group significantly decreased compared with the $\mathrm{VaD}$ group $(p<0.01)$. The therapeutic effect of CH-I-L group and CH-I-M group was better than that of $\mathrm{CH}-\mathrm{I}-\mathrm{H}$ group $(p<0.05)$.

\section{$\mathrm{CH}-\mathrm{I}$ Reduces the Number of Apoptotic Cells in the Hippocampal CAI Region of $\mathrm{VaD}$ Mice}

As shown in Figure 2, compared with sham group, the number of positive hippocampal apoptotic cells in $\mathrm{VaD}$ group increased significantly $(p<0.01)$. After treatment, the number of apoptotic cells in the hippocampal region of

Table 2 Comparison of Memory Ability of Mice in Each Group (\%) $(\bar{X} \pm S)$

\begin{tabular}{|l|c|c|c|}
\hline & $\begin{array}{c}\text { Before } \\
\text { Modeling }\end{array}$ & $\begin{array}{c}\text { After } \\
\text { Modeling }\end{array}$ & $\begin{array}{c}\text { After } \\
\text { Treatment }\end{array}$ \\
\hline Sham & $0.9 \pm 0.09$ & $0.89 \pm 0.08$ & $0.86 \pm 0.09$ \\
$\mathrm{VaD}$ & $0.88 \pm 0.1$ & $0.5 \pm 0.16^{* *}$ & $0.39 \pm 0.15^{* *}$ \\
$\mathrm{CH}-\mathrm{I}-\mathrm{L}$ & $0.9 \pm 0.08$ & $0.46 \pm 0.14^{* *}$ & $0.69 \pm 0.15^{\# \#}$ \\
$\mathrm{CH}-\mathrm{I}-\mathrm{M}$ & $0.87 \pm 0.08$ & $0.48 \pm 0.14^{* *}$ & $0.7 \pm 0.13^{\# \#}$ \\
$\mathrm{CH}-\mathrm{I}-\mathrm{H}$ & $0.85 \pm 0.08$ & $0.45 \pm 0.09^{* *}$ & $0.53 \pm 0.16^{* *}$ \\
$\mathrm{CBL}$ & $0.88 \pm 0.08$ & $0.53 \pm 0.14^{* *}$ & $0.55 \pm 0.15^{* *}$ \\
\hline
\end{tabular}

Notes: ${ }^{* *} p<0.01$ vs sham; ${ }^{\prime \prime} p<0.01$ vs VaD. mice in each treatment group decreased, and the difference was statistically significant compared with $\mathrm{VaD}$ group $(p<0.01)$. Compared with CH-I-H group, CH-I-L group had better treatment effect $(p<0.05)$. However, compared with CBL group, the treatment effect of CH-I-L group and CH-I-M group showed no statistical difference $(p<0.05)$.

\section{Effect of $\mathrm{CH}-\mathrm{I}$ on PI3K, p-PI3K, Akt and $\mathrm{p}-\mathrm{Akt}$ in the Hippocampus of $\mathrm{VaD}$ Mice}

As shown in Figure 3, compared with sham group, the ratios of $\mathrm{p}$-PI3K/PI3K and p-Akt/Akt significantly decreased in $\mathrm{VaD}$ group $(p<0.05)$. After treatment, the ratios of $\mathrm{p}-\mathrm{PI} 3 \mathrm{~K} / \mathrm{PI} 3 \mathrm{~K}$ and $\mathrm{p}$-Akt/Akt significantly increased in CH-I-treated and $\mathrm{CBL}$ groups compared with $\mathrm{VaD}$ group $(p<0.01)$. Moreover, compared with CBL group, the treatment effect of CH-I-L group and CH-I-M group showed no statistical difference $(p<0.05)$.

\section{Effect of $\mathrm{CH}-\mathrm{I}$ on Caspase-9, Caspase-3, $\mathrm{Bcl}-2$ and $\mathrm{Bax}$ in Hippocampus of $\mathrm{VaD}$ Mice}

As shown in Figure 4, compared with sham group, the protein levels of caspase- 9 and caspase-3 in hippocampus of $\mathrm{VaD}$ mice significantly increased $(p<0.01)$, and Bcl-2 protein levels significantly decreased $(p<0.01)$. After treatment, the protein levels of caspase- 9 and caspase-3 in $\mathrm{CH}-$ I-treated group were significantly reduced compared with VaD group $(p<0.01)$, but there was no significant change in the protein levels of CBL group ( $p>0.05)$. Compared with VaD group, the protein levels of $\mathrm{Bcl}-2$ in $\mathrm{CH}-$ I-L group and CH-I-M group significantly increased $(p<0.01)$.

\section{Discussion}

Vascular dementia is one of the sequelae of severe ischemic stroke. VaD development is often associated with chronic cerebral ischemia. ${ }^{27}$ In experimental studies, vascular occlusion is usually used to simulate the process of chronic total cerebral ischemia in patients. In the present study, the modified method of bilateral common carotid artery occlusion was adopted for animal modeling. During the modeling period, the mice showed symptoms such as cyanosis of mouth and extremities, and rapid heart rate, etc. The behavioral test after modeling showed that the learning and memory ability of the model mice decreased. However, after four weeks of continuous CH-I administration, the learning and memory ability of the 

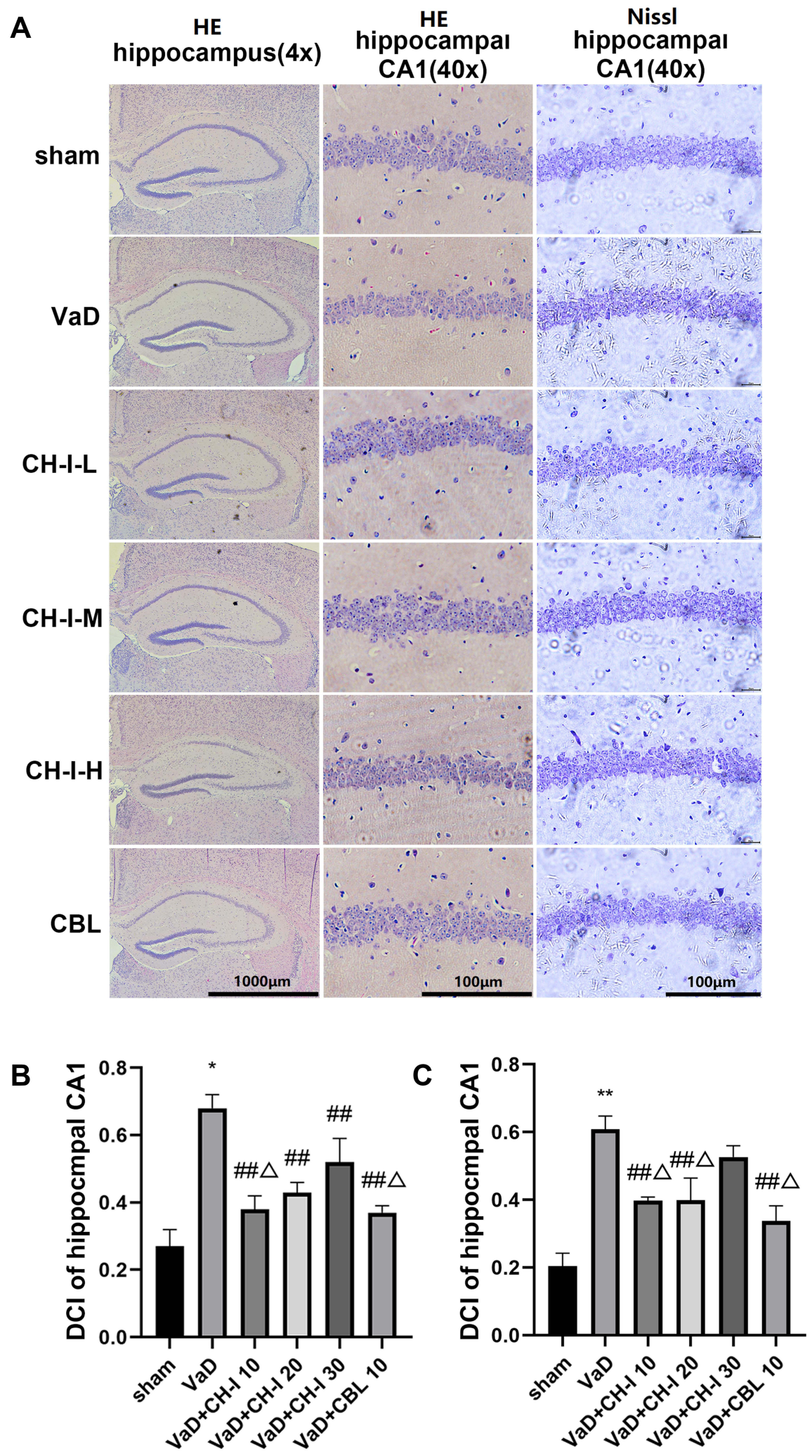

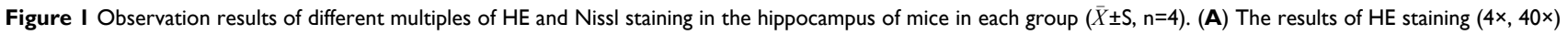
and Nissl staining $(40 \times)$ in the hippocampus of each group; (B and $\mathbf{C})$ Comparison of degeneration cell index of hippocampus CAI of mice in each group; ${ }^{*} p<0.05$ vs sham; ${ }^{* *} p<0.0 \mathrm{I}$ vs sham; ${ }^{\#} p<0.0 \mathrm{I}$ vs $\mathrm{VaD} ;{ }^{\Delta} p<0.05$ vs $\mathrm{CH}-\mathrm{I}-\mathrm{H}$. 


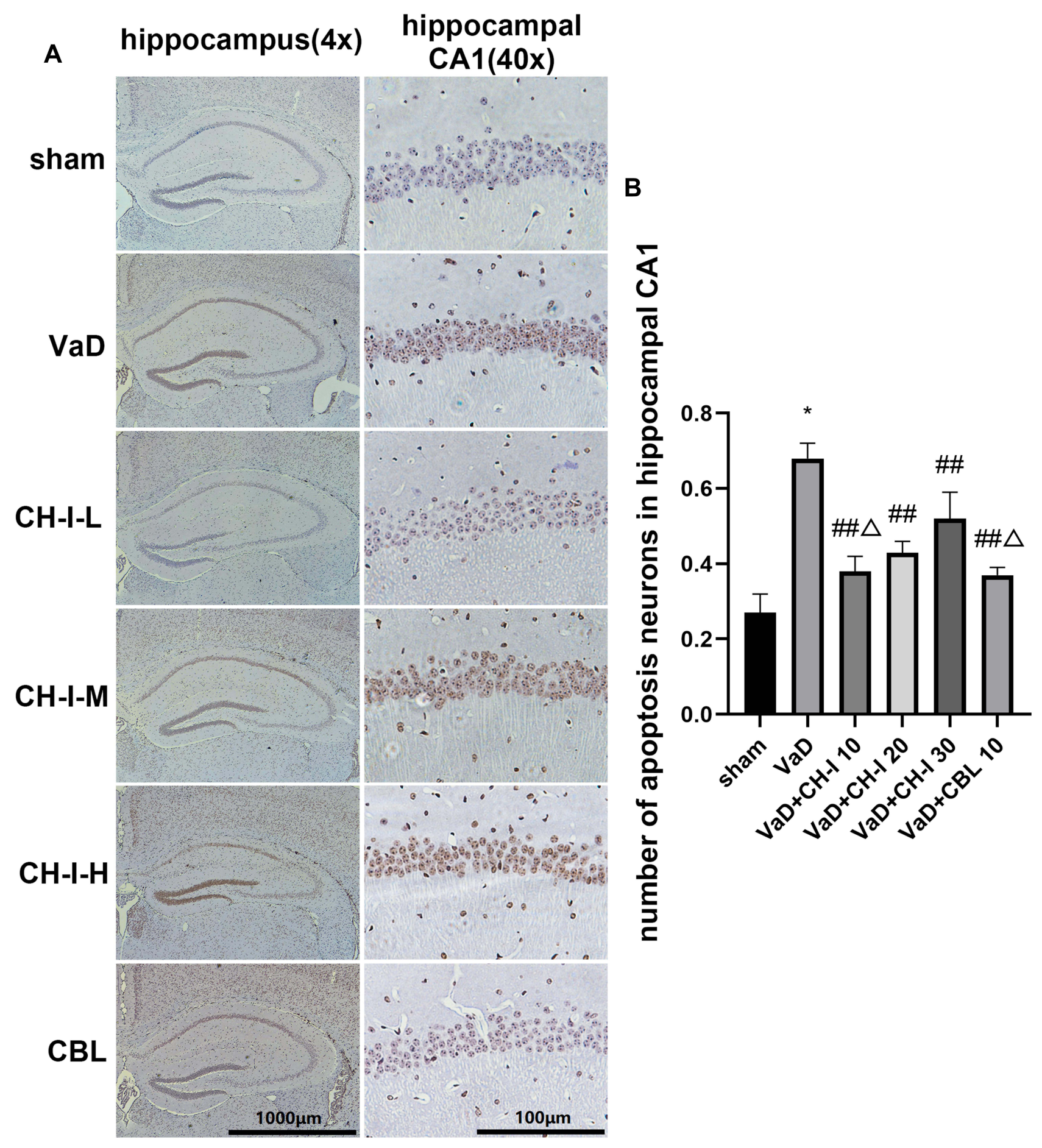

Figure 2 Comparison of the number of neuronal apoptosis in the hippocampus of each group of mice $(\bar{X} \pm S, n=4)$. (A) TUNEL staining (4×, 40×) results of the hippocampus of each group of mice; (B) Comparison of the number of apoptotic neurons in the hippocampus CAI of each group. ${ }^{*} p<0.05$ vs sham; ${ }^{\prime \prime} p<0.01$ vs $V a D ;{ }^{\Delta} p<0.05$ vs $\mathrm{CH}-\mathrm{I}-\mathrm{H}$.

mice in each administration group was better than that of the model group. The anterior hippocampus which is responsible for plot memory and visual scene perception in brain tissue is very sensitive to ischemia. ${ }^{28,29}$ Studies have shown that, after clipping and reperfusion of bilateral common carotid artery, significant loss of neurons was found in the hippocampus CA1 region. ${ }^{30}$ In the present study, the results show that a significant decrease in number in the nerve cells in hippocampal CA1 regions of $\mathrm{VaD}$ mice was accompanied by morphological modifications, such as abnormal morphology, nucleolar shrinkage and disordered arrangement. After CH-I treatment, the number 

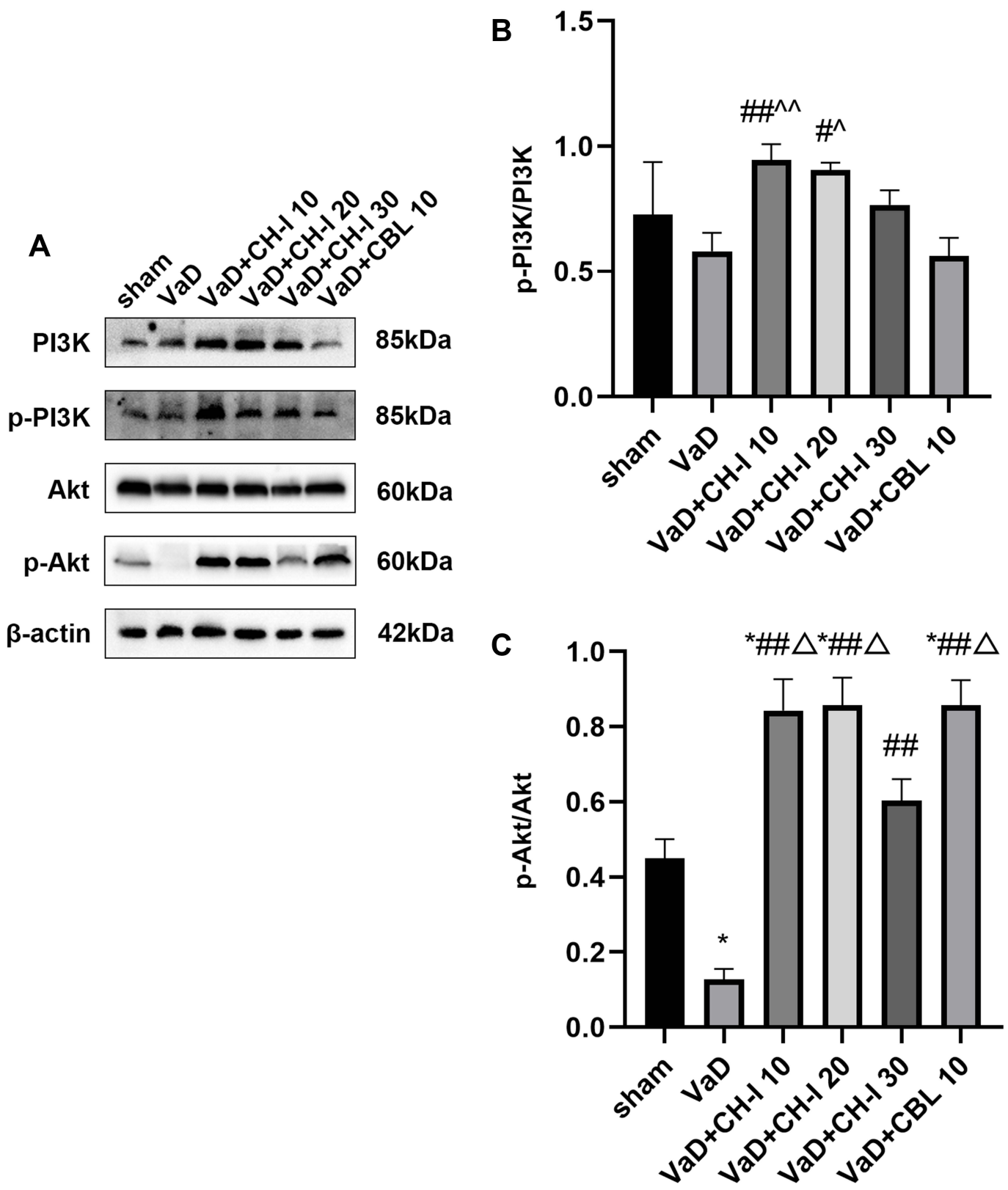

Figure 3 The expression of Akt, p-Akt, PI3K, and p-PI3K in the hippocampus of each group of mice $(\bar{X} \pm \mathrm{S}, \mathrm{n}=4)$. (A) The expression of $A k t, \mathrm{p}-\mathrm{Akt}$, $\mathrm{PI} 3 \mathrm{~K}$, and $\mathrm{p}-\mathrm{PI} 3 \mathrm{~K}$ in the hippocampus of each group; (B) The relative protein expression of $\mathrm{p}-\mathrm{Akt} / \mathrm{Akt}$ in the hippocampus of each group; (C) The relative protein expression of $\mathrm{p}-\mathrm{PI} 3 \mathrm{~K} / \mathrm{PI} \mathrm{KK}$ in the hippocampus of each group. ${ }^{*} p<0.05$ vs sham, ${ }^{\#} p<0.05$ vs $\mathrm{VaD},{ }^{\#} p<0.05$ vs $\mathrm{VaD},{ }^{\Delta} p<0.05$ vs $\mathrm{CH}-\mathrm{I}-\mathrm{H},{ }^{\wedge} p<0.05$ vs $\mathrm{CBL}$, ${ }^{\wedge} p<0.0 \mathrm{I}$ vs $\mathrm{CBL}$.

of abnormal cells decreased, and the nerve cells in hippocampal CA1 regions were protected.

Apoptosis, a type of programmed cell death, is used to accurately regulate the number of cells and eliminate unwanted and potentially dangerous cells. ${ }^{31}$ In the present study, TUNEL assay was used to label the apoptotic cells in the hippocampal region, and it was found that the number of positive cells in the hippocampal CA1 regions increased in $\mathrm{VaD}$ mice, and the number of positive cells in the two regions decreased significantly after CH-I treatment, indicating that $\mathrm{CH}-\mathrm{I}$ can inhibit the apoptosis in hippocampal nerve cells. Intrinsic apoptotic pathways are activated by various intracellular stimuli and depend on apoptotic bodies. Aspartic protease 9 (caspase-9) is one of the components of these apoptotic bodies. In mammalian cells, caspases are the main executor of apoptosis, and their activation is strictly controlled by the B-cell lymphoma-2 (Bcl-2) family protein. A series of members of the family of the Bcl-2 by adjusting the mitochondrial membrane permeability of the release of cytochrome-c 
A

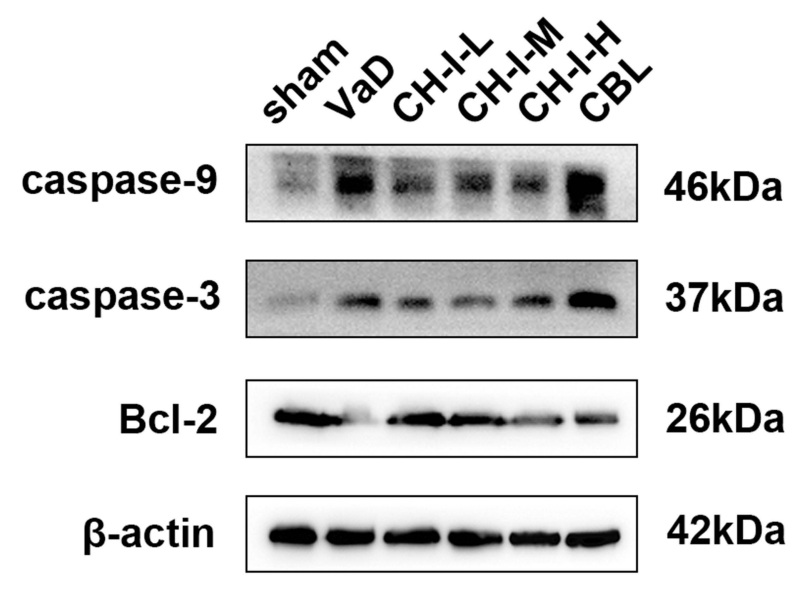

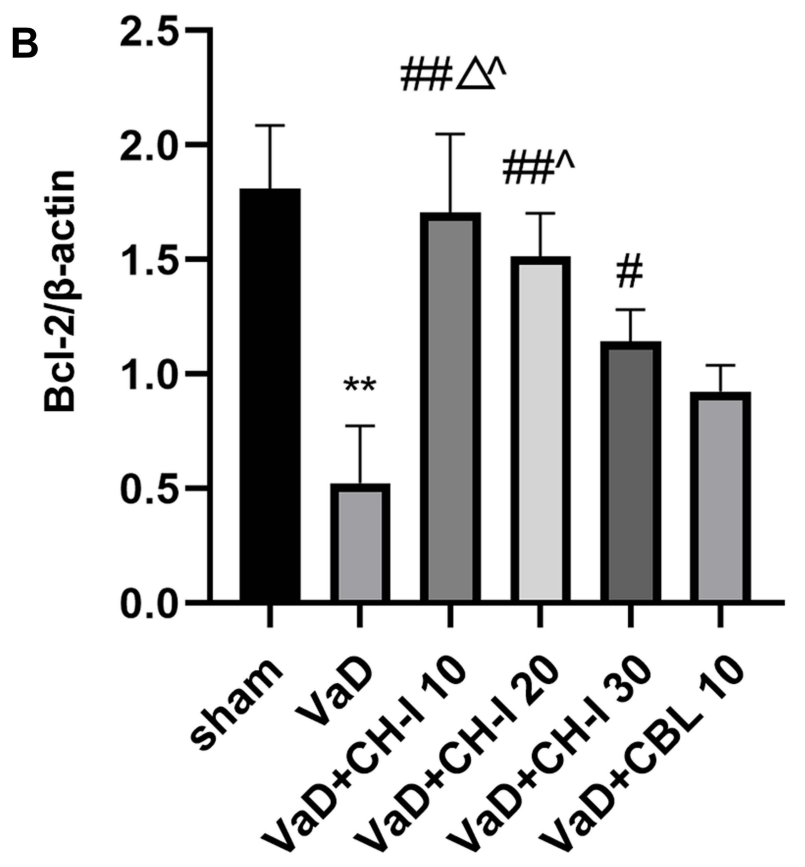

D

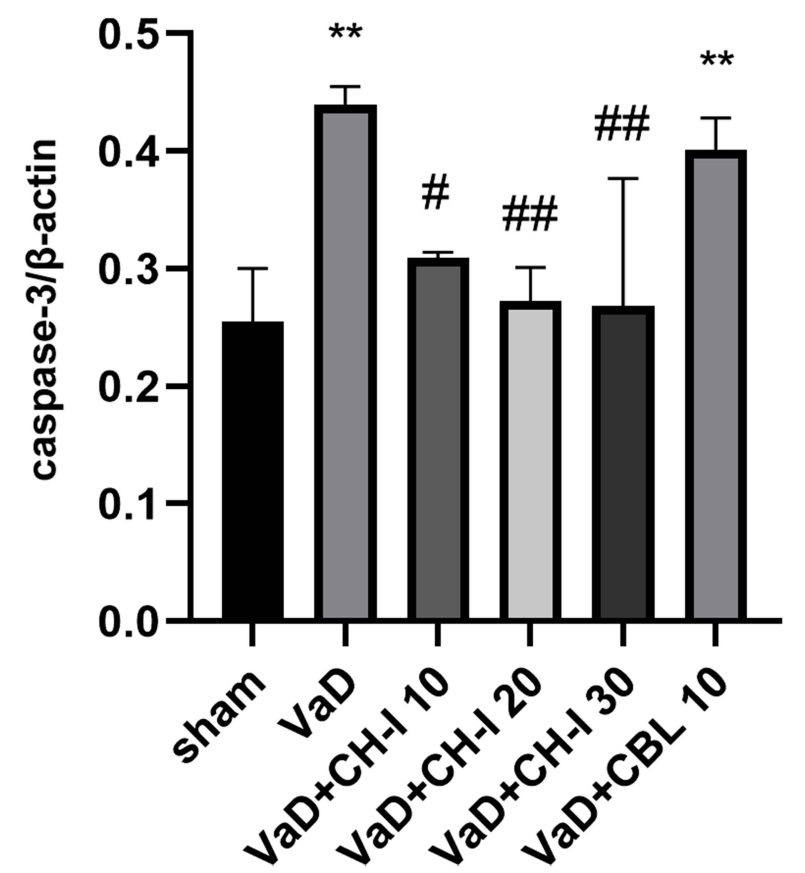

Figure 4 The expression of caspase-9, caspase-3, and Bcl-2 in the hippocampus of each group of mice $(\bar{X} \pm \mathrm{S}, \mathrm{n}=4)$. (A) The expression of caspase-3, caspase-9, and Bcl-2 in the hippocampus of each group; (B) The relative expression of caspase-9 in the hippocampus of each group; (C) The relative expression of caspase- 3 in the hippocampus of each group; (D) The relative expression of $\mathrm{Bcl}-2$ in the hippocampus of each group. ${ }^{* *} p<0.01$ vs sham, ${ }^{\#} p<0.05$ vs $\mathrm{VaD},{ }^{\#} p<0.05$ vs $\mathrm{VaD},{ }^{\Delta} p<0.05$ vs $\mathrm{CH}-\mathrm{I}-\mathrm{H},{ }^{\wedge} p<0.05$ vs $\mathrm{CBL}$.

(Cyt-c), and apoptosis protease activating factor-1 (Apaf1) interaction, cause the activation of caspases-9, leading to subsequent characteristics of cell apoptosis, cell nucleus fragmentation, chromatin condensation, and chromosomal DNA fragmentation. ${ }^{32}$ In the present study, apoptosis of neurons was confirmed by the results of the TUNEL assay and the protein levels of Bcl-2, caspase-9 and caspase-3 in the hippocampal tissues. A phosphoinositide 3 kinase (phosphoinositide 3 kinase, PI3K)/protein kinase $\mathrm{B}$ (protein kinase, $\mathrm{PKB} / \mathrm{Akt}$ ) signaling pathway, which is 
important to promote nerve growth and survival pathways, has been confirmed in many aspects associated with inhibiting apoptosis ${ }^{33,34}$ and promoting neuronal survival. ${ }^{35}$ The results of this study showed that the p-Akt/Akt ratio in the hippocampal tissue of $\mathrm{VaD}$ mice was significantly reduced, while the P-Akt/Akt ratio in each group treated by $\mathrm{CH}-\mathrm{I}$ was significantly increased, indicating that $\mathrm{CH}-\mathrm{I}$ can activate Akt to produce P-Akt and enable it to play an important role in promoting the survival of nerve cells.

In conclusion, our results show that $\mathrm{CH}-\mathrm{I}$ can upregulate $\mathrm{Bcl}-2$ protein and down-regulate the expression of caspase- 9 and caspase- 3 protein in the hippocampal tissues of $\mathrm{VaD}$ mice by activating $\mathrm{Akt}$, and inhibit the apoptosis of hippocampal nerve cells, thus significantly improving the learning and memory functions of $\mathrm{VaD}$ mice. The therapeutic effect was within the dose range of this experiment, and there was no obvious dose-response relationship. The effect of low dose was the best. Compared with the low dose of $\mathrm{CH}-\mathrm{I}$, the same dose of CBL showed the same intensity of up-regulation of p-Akt/ Akt and inhibition of apoptosis of hippocampal nerve cells. However, CBL did not improve the expression of caspase- 9 and caspase- 3 protein in VaD mice, and even further down-regulated the level of Bcl-2 protein. This may be related to the failure of $\mathrm{CBL}$ to improve memory impairment in $\mathrm{VaD}$ mice. Although the total amount of small peptides in $\mathrm{CH}-\mathrm{I}$ and $\mathrm{CBL}$ is the same, the types and proportions of small peptides in each are still unknown. Further chemical and pharmacodynamic studies of the components of CH-I peptides will help to develop more effective drug candidates for the treatment of $\mathrm{VaD}$.

\section{Acknowledgments}

We would like to thank all investigators for their assistance with this study.

\section{Funding}

This work was supported by the Natural Science Fund of China (81973501), Hebei Zhitong Science Fund (2018ZD1901).

\section{Disclosure}

The authors declare no conflicts of interest for this work.

\section{References}

1. Iadecola C, Duering M, Hachinski V, et al. Vascular cognitive impairment and dementia: JACC scientific expert panel. J Am Coll Cardiol. 2019;73(25):3326-3344. doi:10.1016/j.jacc.2019.04.034
2. Vijayan M, Reddy PH. Non-coding RNAs based molecular links in type 2 diabetes, ischemic stroke, and vascular dementia. $J$ Alzheimers Dis. 2020;75(2):353-383. doi:10.3233/JAD-200070

3. O'Brien JT, Thomas A. Vascular dementia. Lancet. 2015;386 (10004):1698-1706. doi:10.1016/S0140-6736(15)00463-8

4. Vijayan M, Kumar S, Bhatti J, Reddy P. Molecular links and biomarkers of stroke, vascular dementia, and Alzheimer's disease. In: Progress in Molecular Biology and Translational Science. Vol. 146. Elsevier; 2017:95-126.

5. Vijayan M, Reddy PH. Stroke, vascular dementia, and Alzheimer's disease: molecular links. J Alzheimers Dis. 2016;54(2):427-443. doi:10.3233/JAD-160527

6. van der Flier WM, Skoog I, Schneider JA, et al. Vascular cognitive impairment. Nat Rev Dis Prim. 2018;4:18003. doi:10.1038/ nrdp.2018.3

7. Appleton JP, Scutt P, Sprigg N, Bath PM. Hypercholesterolaemia and vascular dementia. Clin Sci. 2017;131(14):1561-1578. doi:10.1042/ CS20160382

8. Gustavsson AM, van Westen D, Stomrud E, Engström G, Nägga K, Hansson O. Midlife atherosclerosis and development of Alzheimer or vascular dementia. Ann Neurol. 2020;87(1):52-62. doi:10.1002/ ana. 25645

9. Simonetto M, Infante M, Sacco RL, Rundek T, Della-Morte D. A novel anti-inflammatory role of omega-3 PUFAs in prevention and treatment of atherosclerosis and vascular cognitive impairment and dementia. Nutrients. 2019;11(10):2279. doi:10.3390/ nu11102279

10. Becker E, Orellana Rios CL, Lahmann C, Rücker G, Bauer J, Boeker M. Anxiety as a risk factor of Alzheimer's disease and vascular dementia. $\mathrm{Br} \quad J \quad$ Psychiatr. 2018;213(5):654-660. doi:10.1192/bjp.2018.173

11. Xia DJ, Sui RB, Min LQ, Zhang L, Zhang Z. Fastigial nucleus stimulation ameliorates cognitive impairment via modulating autophagy and inflammasomes activation in a rat model of vascular dementia. J Cell Biochem. 2019;120(4):5108-5117. doi:10.1002/ jcb. 27787

12. Jiang X, Niu XL, Guo QJ, et al. FoxO1-mediated autophagy plays an important role in the neuroprotective effects of hydrogen in a rat model of vascular dementia. Behav Brain Res. 2019;356:98-106. doi:10.1016/j.bbr.2018.05.023

13. Huo T, Jia Y, Yin C, et al. Iron dysregulation in vascular dementia: focused on the AMPK/autophagy pathway. Brain Res Bull. 2019;153:305-313. doi:10.1016/j.brainresbull.2019.09.006

14. Liu QQ, Zhong D, Zhang X, Li GZ. IL-10 targets Th1/Th2 balance in vascular dementia. Eur Rev Med Pharmacol Sci. 2018;22 (17):5614-5619. doi:10.26355/eurrev_201809_15826

15. Han XR, Wen X, Wang YJ, et al. Effects of CREB1 gene silencing on cognitive dysfunction by mediating PKA-CREB signaling pathway in mice with vascular dementia. Mol Med. 2018;24(1):18-29. doi:10.1186/s10020-018-0020-y

16. Gavrilova SI, Alvarez A. Cerebrolysin in the therapy of mild cognitive impairment and dementia due to Alzheimer's disease: 30 years of clinical use. Med Res Rev. 2020.

17. Brainin M. Cerebrolysin: a multi-target drug for recovery after stroke. Expert Rev Neurother. 2018;18(8):681-687. doi:10.1080/ 14737175.2018.1500459

18. Zhang L, Chopp M, Wang CY, et al. Prospective, double blinded, comparative assessment of the pharmacological activity of Cerebrolysin and distinct peptide preparations for the treatment of embolic stroke. J Neurol Sci. 2019;398:22-26. doi:10.1016/j. jns.2019.01.017

19. Cao W, Zhang C, Chen R, et al. A novel cerebroprotein hydrolysate, $\mathrm{CH} 1$, ameliorates chronic focal cerebral ischemia injury by promoting white matter integrity via the Shh/Ptch-1/Gli-1 signaling pathway. Neuropsychiatr Dis Treat. 2020;16:3209-3224. doi:10.2147/NDT. S289990 
20. Chen N, Yang M, Guo J, Zhou M, Zhu C, He L. Cerebrolysin for vascular dementia. Cochrane Database Syst Rev. 2013;(1). doi:10.1002/14651858.CD008900.pub2

21. Xing SH, Zhang J, Dang C, et al. Cerebrolysin reduces amyloid- $\beta$ deposits, apoptosis and autophagy in the thalamus and improves functional recovery after cortical infarction. J Neurol Sci. 2014;337 (1-2):104-111. doi:10.1016/j.jns.2013.11.028

22. Zhang YL, Chopp M, Zhang ZG, et al. Cerebrolysin reduces astrogliosis and axonal injury and enhances neurogenesis in rats after closed head injury. Neurorehabil Neural Repair. 2019;33(1):15-26. doi:10.1177/1545968318809916

23. Zhang H, Han T, Zhang L, et al. Effects of tenuifolin extracted from radix polygalae on learning and memory: a behavioral and biochemical study on aged and amnesic mice. Phytomedicine. 2008;15 (8):587-594. doi:10.1016/j.phymed.2007.12.004

24. Wei XM, Yang W, Liu LX, Qi WX. Effects of L-arginine and N( $\omega)$ nitro-L-arginine methylester on learning and memory and $\alpha 7 \mathrm{nAChR}$ expression in the prefrontal cortex and hippocampus of rats. Neurosci Bull. 2013;29(3):303-310. doi:10.1007/s12264-013-1331-1

25. Mori MA, Meyer E, Soares LM, Milani H, Guimarães FS, de Oliveira RMW. Cannabidiol reduces neuroinflammation and promotes neuroplasticity and functional recovery after brain ischemia. Prog Neuropsychopharmacol Biol Psychiatry. 2017;75:94-105. doi:10.1016/j.pnpbp.2016.11.005

26. Siracusa R, Impellizzeri D, Cordaro M, et al. Anti-inflammatory and neuroprotective effects of co-ultraPEALut in a mouse model of vascular dementia. Front Neurol. 2017;8:233. doi:10.3389/ fneur.2017.00233

27. Zhou D, Meng R, Li SJ, et al. Advances in chronic cerebral circulation insufficiency. CNS Neurosci Ther. 2018;24(1):5-17. doi:10.1111/ cns. 12780
28. Knierim JJ. The hippocampus. Curr Biol. 2015;25(23):R1116-1121. doi:10.1016/j.cub.2015.10.049

29. Zeidman P, Maguire EA. Anterior hippocampus: the anatomy of perception, imagination and episodic memory. Nat Rev Neurosci. 2016;17(3):173-182. doi:10.1038/nrn.2015.24

30. Guan XY, Li XL, Yang XJ, et al. The neuroprotective effects of carvacrol on ischemia/reperfusion-induced hippocampal neuronal impairment by ferroptosis mitigation. Life Sci. 2019;235:116795. doi:10.1016/j.1fs.2019.116795

31. Estaquier J, Vallette F, Vayssiere JL, Mignotte B. The mitochondrial pathways of apoptosis. In: Scatena R, Bottoni P, Giardina B, editors. Advances in Mitochondrial Medicine. Dordrecht: Springer Netherlands; 2012:157-183.

32. Su ZY, Yang ZZ, Xu YQ, Chen YB, Yu Q. Apoptosis, autophagy, necroptosis, and cancer metastasis. Mol Cancer. 2015;14(1):48-61. doi:10.1186/s12943-015-0321-5

33. Li H, Song F, Duan LR, et al. Paeonol and danshensu combination attenuates apoptosis in myocardial infarcted rats by inhibiting oxidative stress: roles of Nrf2/HO-1 and PI3K/Akt pathway. Sci Rep. 2016;6(1):23693. doi:10.1038/srep23693

34. Miao Y, Zheng W, Li NN, et al. MicroRNA-130b targets PTEN to mediate drug resistance and proliferation of breast cancer cells via the PI3K/Akt signaling pathway. Sci Rep. 2017;7(1):41942. doi:10.1038/ srep41942

35. Zhang T, Gu J, Wu L, et al. Neuroprotective and axonal outgrowth-promoting effects of tetramethylpyrazine nitrone in chronic cerebral hypoperfusion rats and primary hippocampal neurons exposed to hypoxia. Neuropharmacology. 2017;118:137-147. doi:10.1016/j.neuropharm.2017.03.022
Neuropsychiatric Disease and Treatment

\section{Publish your work in this journal}

Neuropsychiatric Disease and Treatment is an international, peerreviewed journal of clinical therapeutics and pharmacology focusing on concise rapid reporting of clinical or pre-clinical studies on a range of neuropsychiatric and neurological disorders. This journal is indexed on PubMed Central, the 'PsycINFO' database and CAS, and

\section{Dovepress}

is the official journal of The International Neuropsychiatric Association (INA). The manuscript management system is completely online and includes a very quick and fair peer-review system which is all easy to use. Visit http://www.dovepress.com/testimonials.php to read real quotes from published authors. 